\title{
Pressure gradient measurement in the coronary artery using 4D PC-MRI: towards noninvasive quantification of fractional flow reserve
}

\author{
Zixin Deng ${ }^{1,2^{*}}$, Zhaoyang Fan ${ }^{1}$, Guoxi Xie ${ }^{3}$, Yi He ${ }^{4}$, Yutaka Natsuaki ${ }^{5}$ Ning $\mathrm{Jin}^{5}$, Xiaoming $\mathrm{Bi}^{5}$, Jing $\mathrm{An}^{5}$, Xin $\mathrm{Liu}^{3}$, \\ Zhaoqi Zhang ${ }^{4}$, Zhanming Fan ${ }^{4}$, Debiao Li $\mathrm{Li}^{1,2}$
}

From 17th Annual SCMR Scientific Sessions

New Orleans, LA, USA. 16-19 January 2014

\section{Background}

Fractional flow reserve (FFR) is an invasive procedure evaluating the functional significance of an intermediate stenosis by measurement of pressure drop across stenosis [1]. Noninvasive pressure measurement technique i.e. Phase-contrast (PC)-MRI has been studied in the cardiac chamber[2], aorta[3], and renal[4] arteries. The purpose of this study was to investigate the feasibility of pressure gradient quantification using 4DPC-MRI in the coronary arteries, which may allow for the derivation of FFR associated with stenosis.

\section{Methods}

A 4D PC-MRI sequence with an acquisition window at the mid-diastole and end-expiration phase using ECG-triggering and navigator-gating to minimize motion-induced errors was implemented on a 3T system (MAGNETOM Verio, Siemens). The sequence measures the 4D flow velocity field through a cross-sectional 3D acquisition, in conjunction with the Navier-Stokes equations[2] to calculate the pressure gradient within the vessel segment of interest. A flow phantom study (gadolinium-doped water flow at a constant volume velocity of $250 \mathrm{~mL} / \mathrm{min}$ in a silicone tubing of 4.8-mm ID) was first performed to determine the feasibility of the technique to detect changes in pressure difference $(\Delta \mathrm{P})$ at six different stenosis cases: $0,22 \%, 34 \%$, $44 \%, 60 \%, 64 \%$ with appropriate combinations of VENCs in $\mathrm{z}(45,60, \ldots, 200 \mathrm{~cm} / \mathrm{s})$ and $\mathrm{x}, \mathrm{y}(20,30, \ldots, 80 \mathrm{~cm} / \mathrm{s})$ directions. The sequence was then tested in 3 healthy male volunteers using a VENC of $90 \mathrm{z} 40 \mathrm{x} 40 \mathrm{y}$ on the left main, LCX and 60z30x30y on the proximal LAD, respectively. Imaging parameters for human studies were: spatial resolution $=0.78 \times 0.78 \times 2.00 \mathrm{~mm}^{3}$, flip angle $=$ $15^{\circ}$, cardiac phase $=2-3(77 \mathrm{~ms} /$ phase $)$ coinciding with the quiescent period, scan time $=11-18$ mins.

\section{Results}

Phantom studies: 16 contiguous slices were acquired spanning the stenosis area. $\Delta \mathrm{P}$ between the most stenotic slice and the reference (2nd) slice increased with the stenosis degree, as illustrated in Figure 1. Volunteer studies: 6 contiguous slices were acquired per volunteer. Figure 2 illustrates the flow compensated (reference) and phase difference $(x, y, z)$ images of one volunteer from 2 successive cardiac phases during the mid-diastole, where the yellow arrows are pointing at the cross-sections of the coronary artery. Cardiac phases in the $\mathrm{z}$ - and $\mathrm{x}$, $y$-direction differed by $6-15 \mathrm{~cm} / \mathrm{s}$ and $0.5-5 \mathrm{~cm} / \mathrm{s}$, respectively. $\Delta \mathrm{P}$ values between slices 2 and 5 were $0.1646,0.1407$ and $0.2259 \mathrm{mmHg}$ in the 3 volunteers, respectively.

\section{Conclusions}

The preliminary results have suggested that quantification of pressure gradient in the coronary artery is feasible. As expected, healthy volunteers showed a near zero pressure gradient across the coronary arteries. Animal and clinical validations on real coronary stenosis are currently underway. Further technical improvements such as temporal/ spatial resolution are warranted.

\section{Funding}

NHLBI HL38698, NIBIB EB002623. 


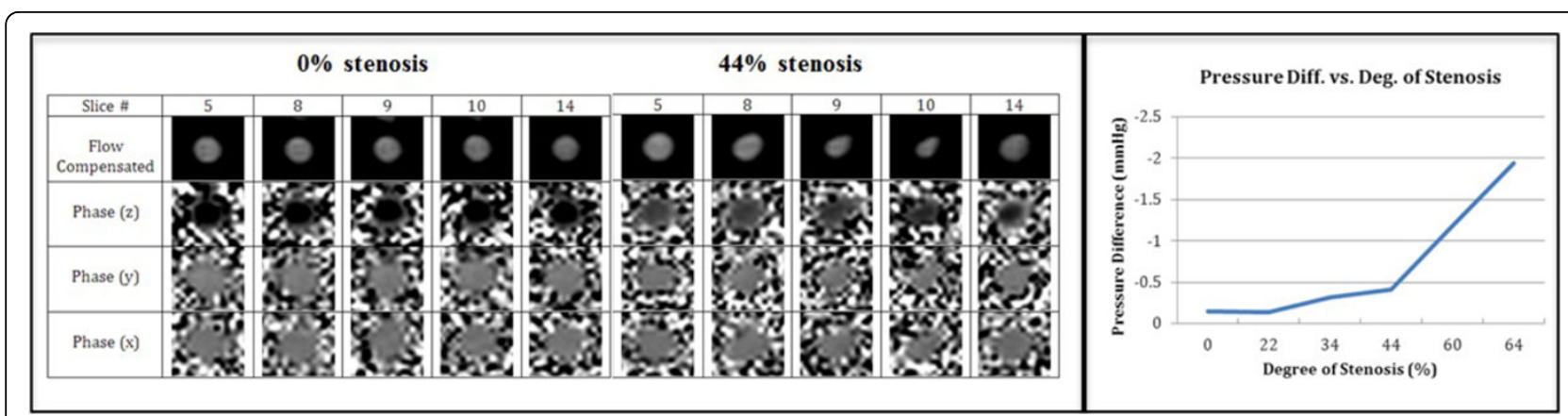

Figure 1 Example images for flow phantom at $0 \%$ and $44 \%$ stenosis and pressure difference curve in phantom showing the pressure difference between the most stenotic slice and the reference ( 2 nd) slice increased with the degree of stenosis

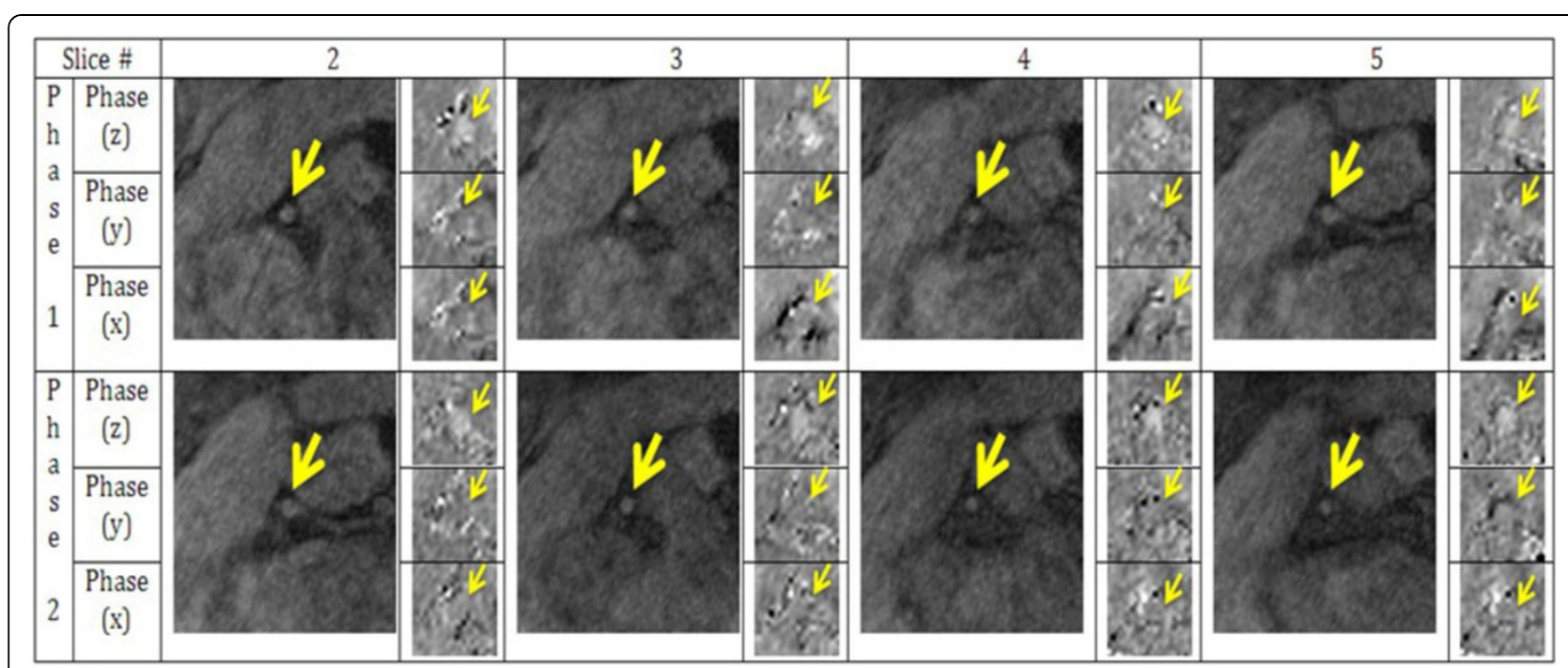

Figure 2 Example images of flow compensated (reference) and phase difference $(x, y, z)$ images for two cardiac phases in a healthy volunteer.

\section{Authors' details}

${ }^{1}$ Biomedical Imaging Research Institute, Cedars Sinai Medical Center, Los

Angeles, California, USA. ${ }^{2}$ Department of Bioenginnering, University of California, Los Angeles, Los Angeles, California, USA. ${ }^{3}$ Shenzhen Institutes of Advanced Technology, Chinese Academy of Science, Shenzhen, China.

${ }^{4}$ Department of Radiology, Anzhen Hospital, Beijing, China. ${ }^{5}$ R\&D, Siemens Healthcare, Los Angeles, California, USA.

Published: 16 January 2014

\section{References}

1. Tonino, et al: NEJM 2009, 360:213-24.

2. Thompson, et al: MRM 2003, 49:1056-66.

3. Tyszka, et al: JMRI 2000, 12:321-29.

4. Bley, et al: Radiology 2011, 261:266-73.

\section{doi:10.1186/1532-429X-16-S1-055}

Cite this article as: Deng et al:: Pressure gradient measurement in the coronary artery using 4D PC-MRI: towards noninvasive quantification of fractional flow reserve. Journal of Cardiovascular Magnetic Resonance 2014 16(Suppl 1):055.

Submit your next manuscript to BioMed Central and take full advantage of:

- Convenient online submission

- Thorough peer review

- No space constraints or color figure charges

- Immediate publication on acceptance

- Inclusion in PubMed, CAS, Scopus and Google Scholar

- Research which is freely available for redistribution 